\title{
Thermospheric meridional wind at low latitude from measurements of $F$ layer peak height
}

\author{
R. T. de Medeiros \\ Universidade Federal do Rio Grande do Norte, Natal, Brazil \\ M. A. Abdu and I. S. Batista \\ Instituto Nacional de Pesquisas Espaciais, São José dos Campos, Brazil
}

\begin{abstract}
Thermospheric meridional winds are calculated in this paper for the low-latitude station, Cachoeira Paulista, in Brazil using ionospheric $F$ layer peak height $h_{\max }$ as the primary database for different seasons and solar activity conditions. A servo model is used that expresses the ionospheric $F$ layer peak height displacements as a function of chemical loss, diffusion, thermospheric meridional wind and vertical plasma drift. The method used is similar to, and an extension of, the one used in recent years for midlatitudes, where the effect of vertical plasma drift is considered negligible. We have included in our analysis the effect of vertical plasma drift on $h_{\max }$ over Cachoeira Paulista by using a vertical drift model which is a field line extension of an equatorial electric field model developed for our longitude, for which the radar data from Jicamarca, Peru, are complemented, in the sunset sector, by vertical drift from ionosonde data over Fortaleza. A numerical model on the electrodynamic coupling of the $E$ and $F$ regions is used to obtain the equatorial height dependence of the vertical drift needed for its field line mapping to low latitude. Meridional winds were calculated using the servo equations in which the vertical plasma drifts, and $h_{\max }$ values deduced from Cachoeira Paulista ionograms, were the main inputs. The magnetic meridional winds calculated for the summer equinoctial and winter months of high and low solar activity epochs are compared with the HWM-90 and with the measurements by Fabri-Perot technique available for Cachoeira Paulista. The results show varying agreements. The paper presents details of the method of analysis and the comparison of the results.
\end{abstract}

\section{Introduction}

Thermospheric meridional wind has been determined from ionosonde $h_{m} F_{2}$ data for midlatitudes with good degree of success, using an adaptation of the servo method [Rishbeth et al., 1978] by Miller et al. [1986, 1987, 1989]. According to the servo model the height of the $F_{2}$ layer peak density, in the absence of forcing from wind or electric field, is under equilibrium between recombination and diffusion processes. An equatorward blowing wind forces the layer upward, thereby enhancing the downward diffusion of ionization that opposes the layer upward displacement. On the other hand, a poleward wind forces the layer downward to a region of higher recombination which in turn could oppose additional downward displacement of the layer. Miller et al. [1986] used the ionospheric model by Richards and Torr [1985, 1988] and Young et al. [1980] to establish a linear relationship between the meridional wind and the $F_{2}$ layer peak height that was then used to deduce the meridional wind from $h_{m} F_{2}$ data obtained from ionograms for midlatitude locations. Over low latitudes the dominant $h_{m} F_{2}$ (or $h_{\max }$ ) variations are produced by meridional winds as well as by electric fields, and as a result the method of Miller et al. [1986] has not so far been applied to $h_{\max }$ data over low-latitude locations. On the other hand, the information on meridional winds over equatorial low-latitude regions is quite valuable as it could contribute to

Copyright 1997 by the American Geophysical Union.

Paper number 97JA00799.

0148-0227/97/97JA-00799\$09.00 a better understanding of the functioning of the major phenomena of the equatorial ionosphere-thermosphere system, such as the equatorial ionization anomaly and the equatorial spread $F /$ plasma bubble events. Here we present a method to use the servo model for low-latitude conditions, which involves a procedure to account for the electric field induced variations of the $F_{2}$ peak height, thus permitting the determination of the meridional wind based on $h_{\max }$ data from low-latitude ionograms. The servo equations are used in its time dependent form, and the nonlinear terms are maintained. The meridional winds were calculated based on the ionogram data for Cachoeira Paulista $\left(45^{\circ} \mathrm{W}, 23^{\circ} \mathrm{S}\right.$, dip angle: $\left.-30^{\circ}\right)$ for December solstice, June solstice, and equinoctial months and for solar maximum and minimum conditions. The number of days used for each season and their distribution as a function of solar activity, represented by solar flux values, $F_{107}$, and magnetic activity conditions, represented by $\Sigma K p$ averaged for the days used in each season, are presented in Figure 1. The validity of the meridional wind calculated from the $h_{\max }$ data sets are then checked by comparing the results with the semiempirical model, HWM-90 (Horizontal Wind Model) of Hedin et al. [1991] and with the data available from FabriPerot interferometer measurements carried out over Cachoeira Paulista.

\section{Method of Analysis}

Based on Rishbeth et al. [1978], the equation that controls the movement of the $F_{2}$ peak is given by 


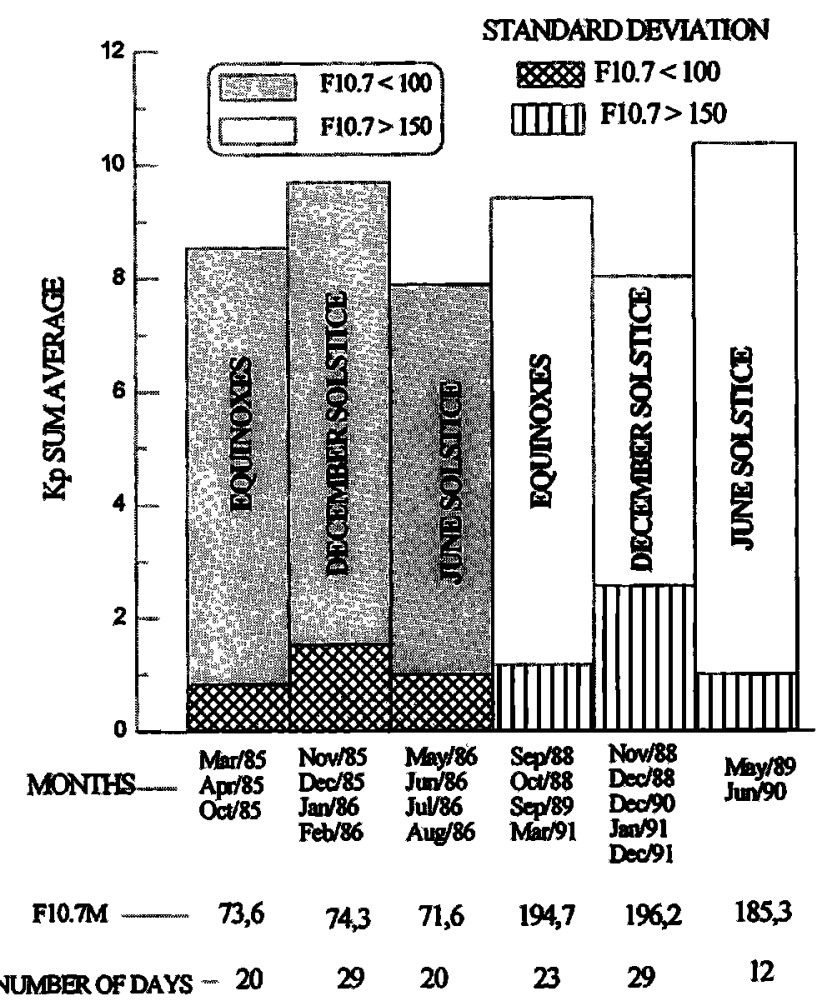

Figure 1. Distribution of the data used in the analysis as a function of daily sum of $K p\left(\sum K_{p}\right)$ for different solar activity levels and seasons. Solar activity levels are indicated by the $F_{10.7}$ flux values shown below the histograms for equinoxes, December- and June-solsticial months. Standard deviations in the $\sum K_{p}$ values for each group are shown hatched.

$$
\frac{d Z_{m}}{d t}=(1-a) \frac{q e^{-z}}{N_{m}}+\frac{D_{e, s} \sin ^{2} I}{2 H^{2}}\left[\lambda e^{-k Z_{m}}-e^{Z_{m}}\right]+\frac{W}{H}
$$

where $\lambda=(k a c-1) /(k c-1) ; W$ is the ionization drift from the meridional wind $U_{M}$ and electric field $E ; k=1.75$ (as used by Rishbeth et al. [1978]); and $D_{c}$ and $D_{s}$ represent the diffusion coefficients during the day and night, respectively. Since the production term is small and $Z_{m}=\left(h_{m}-h_{0}\right) / H$, equation (1) can be rewritten as

$$
\frac{d h_{m}}{d t}=\frac{D_{e, s} \sin ^{2} I}{2 H}\left[\lambda e^{-k\left(\frac{h_{m}-h_{0}}{H}\right)}-e^{\frac{h_{m}-h_{0}}{H}}\right]+W
$$

where $\lambda$ is taken as 1 for nighttime conditions and 3.86 for daytime conditions, with a linear transition between 0600 and $1000 \mathrm{LT}$ and between 1400 and $1800 \mathrm{LT}, a$ and $c$ are constants [see Rishbeth et al., 1978], and $H$ is the scale height of the ionizable gas. The layer peak height in the absence of plasma drift and transport, that is, under equilibrium between recombination and diffusion, is denoted by $h_{0}$ and, as shown by Rishbeth et al. [1978], $\beta=D_{e, s} \sin ^{2} I /\left[2 H^{2}(k a c-1) / k\right]$. Since $W=V_{z} \cos I+U_{M} \cos I \sin I, U_{M}$ from (2) can be written as

$$
U_{M}=\frac{1}{\cos I \sin I} \frac{d h_{m}}{d t}+\frac{H}{(k+1) \alpha}\left[e^{\frac{h_{m}-h_{0}}{H}}-\lambda e^{-k \frac{h_{m}-h_{0}}{H}}\right]-\frac{V_{z}}{\sin I}
$$

where

$$
\alpha=\frac{2 H^{2} \cos I}{(k+1) D_{e, s} \sin I} \mathrm{~km} / \mathrm{m} / \mathrm{s}
$$

The three terms of the right-hand side of (3) contribute to $U_{M}$ in varying degrees, their significance depending upon local time. It should be noted here that by meridional wind we mean wind in the magnetic meridian. In order to calculate the meridional wind it is necessary to evaluate carefully the three critical parameters: $V_{z}, h_{m} F_{2}$ and $h_{0}$. Their evaluations as functions of local time and representative of the quiet conditions of the different seasons and solar activity levels are described below.

\section{Vertical Drift Velocity/ Electric Field Model}

Over low latitudes the observed $h_{\max }$ values could be significantly influenced by electrodynamic drift of the plasma driven by equatorial electric fields. The use of $h_{\max }$ values for calculating the meridional wind would therefore depend on how best we could account for its variations arising from the vertical drift velocity $V_{z}$. Over Cachoeira Paulista where the $h_{\max }$ measurements are obtained from an ionosonde, we do not have direct electric field measurements. Therefore an electric field/vertical drift model is constructed for this station that is based on a model for the equatorial station Fortaleza situated within close by longitude with respect to this station. Even though the large magnetic declination angles of these stations $\left(21^{\circ} \mathrm{W}\right.$ for Fortaleza and $19^{\circ} \mathrm{W}$ for Cachoeira Paulista) cause their separation larger in magnetic longitude than in geographic longitude, we are quite safe in assuming that the electric field model for Fortaleza could be as valid as a base for a model for Cachoeira Paulista as though the former station is located nearly in the same magnetic meridian as that of the latter. However, due consideration is given to the existence of marked longitudinal dependence of the vertical drift, driven by $F$ layer dynamo electric field around sunset to premidnight hours, arising from the large variation of the magnetic declination angle that characterizes the South American longitude sector between Peru and Brazil (the declination angle varies from $4^{\circ} \mathrm{E}$ at Jicamarca to $21^{\circ} \mathrm{W}$ at Fortaleza) as shown in our previous studies [Abdu et al., 1981; Batista et al., 1986].

The development of a model for vertical drift over Cachoeira Paulista consisted of the following steps: (1) determination of a vertical drift pattern for the magnetic equatorial region over Fortaleza based on the Jicamarca radar data and the ionosonde data over Fortaleza; (2) use of an electrodynamic model on $E$ and $F$ region coupling that calculates the vertical gradients in the vertical drift velocity over the equator; (3) comparison of the model results from step 2 with available results of such gradients from Jicamarca radar and then the use of these gradients together with the results from step 1 to obtain, by extrapolation, the vertical drift at the apex height of the field line that maps to the $F$ region peak heights over Cachoeira Paulista.

Equatorial $F$ region vertical plasma drift velocities have been extensively studied using radar, satellite, and ionosonde data sets [see, e.g., Fejer et al., 1979, 1991, 1995; Abdu et al., 1981; Batista et al., 1986, 1996; Balan et al., 1992]. Also, it is now well established that the $F$ region vertical drift in the South American equatorial region presents significant longitudinal variation around sunset and premidnight hours, as was shown by comparing the drift result from Jicamarca radar with those calculated from ionosonde data over Fortaleza [Abdu et al., 1981; Batista et al., 1986]. Therefore the diurnal pattern of the $V_{z}$ over Jicamarca is considered to 
be valid for Fortaleza only for local times excluding the hours from $1645 \mathrm{LT}$ to $2200 \mathrm{LT}$. The electric field during these hours is strongly under the influence of the evening $F$ layer dynamo whose development is significantly influenced by the magnetic declination angle that is different at Fortaleza $\left(22^{\circ} \mathrm{W}\right)$ compared to that of Jicamarca $\left(4^{\circ} \mathrm{E}\right)$ [see $A b d u$ et al., 1981; Batista et al., 1986]. The $V_{z}$ values during these hours are based on the $F$ region vertical drift deduced as $d h^{\prime} F / d i$ from 15-min interval ionograms over Fortaleza. It has been shown by Bittencourt and $A b d u$ [1981] that the value of $d h^{\prime} F / d t$ is a valid representation of the $F$ region vertical drift for $h^{\prime} F \geq 300 \mathrm{~km}$. For $h^{\prime} F<300 \mathrm{~km}$ a correction for recombination effect represented by a term, $\beta H$ has been applied (where $\beta$ is the attachment coefficient and $H$ is the ionospheric scale height). On the above basis the $V_{z}$ diurnal pattern for the equatorial station Fortaleza was constructed for the three seasons, December solstice (D months), equinoxes, and June solstice ( $\mathrm{J}$ months), for high and low solar activity conditions represented by solar flux values, $F_{10.7}>150$ and $F_{10.7}<100$, respectively.

The $V_{z}$ diurnal variation representative of high solar flux values $\left(F_{10.7}>150\right)$ are presented as solid lines in Figures $2 \mathrm{a}$, $2 \mathrm{~b}$, and $2 \mathrm{c}$ for the $\mathrm{D}$ months, equinoxes, and $\mathrm{J}$ months, respectively. The model represents the vertical drift at a mean altitude of $350 \mathrm{~km}$. It may be noted that the daytime vertical drift has highest values in equinoxes and the lowest values in $\mathrm{D}$ months, with intermediate values for $\mathrm{J}$ months, whereas the prereversal enhancement amplitude is largest in D months and smallest in J months. Another notable feature is that the local time of the peak in the vertical drift occurs significantly later in J months as compared to the $\mathrm{D}$ months and equinoxes.

Figures $3 a, 3 b$, and $3 c$ present (solid line) the vertical drift pattern over Fortaleza for the three seasons and for low solar flux $\left(F_{10.7}<100\right)$. The amplitudes of the prereversal drift enhancement and nighttime downward drift is significantly smaller during the solar minimum as compared to the results for solar maximum (Figure 2), which is in general agreement with the solar cycle dependence of these drifts presented by Fejer et al. [1991]. We may note further that the J months of solar minimum presents almost total absence of prereversal enhancement electric field which had significant amplitude during solar maximum.

The vertical drift pattern over the equatorial station, Fortaleza, is used as a basis for determining, from knowledge of its vertical gradient, its corresponding pattern at the $h_{\max }$ altitude over Cachoeira Paulista which corresponds to $\sim 650$ $\mathrm{km}$ apex height over the equator. The height gradient used for extrapolating the $V_{z}$ at $350 \mathrm{~km}$ over Fortaleza to a height of $650 \mathrm{~km}$ is calculated using an $E$ and $F$ region electrodynamic coupling model (see Batista et al. [1986] and Heelis et al. [1974] for details). Although the numerical code calculates the vertical drift up to $500 \mathrm{~km}$, we have assumed linear trend in the $V_{z}$ height profile, that is, constant gradient, until 650 $\mathrm{km}$, even though such an assumption may not be rigorously valid for all local time. The diurnal pattern of the vertical drift height gradient at $650 \mathrm{~km}$ obtained from this procedure is presented for the three seasons and for the solar maximum and minimum conditions in Figures $4 a$ and $4 b$, respectively. These gradients show general agreement with the available results from Jicamarca radar [see, e.g., Pingree and Fejer, 1987; Abdu et al., 1992]. The model results show negative gradient with height in the vertical drift from $\sim 1700 \mathrm{LT}$ to $2200 \mathrm{LT}$, that is, centered around the prereversal electric field

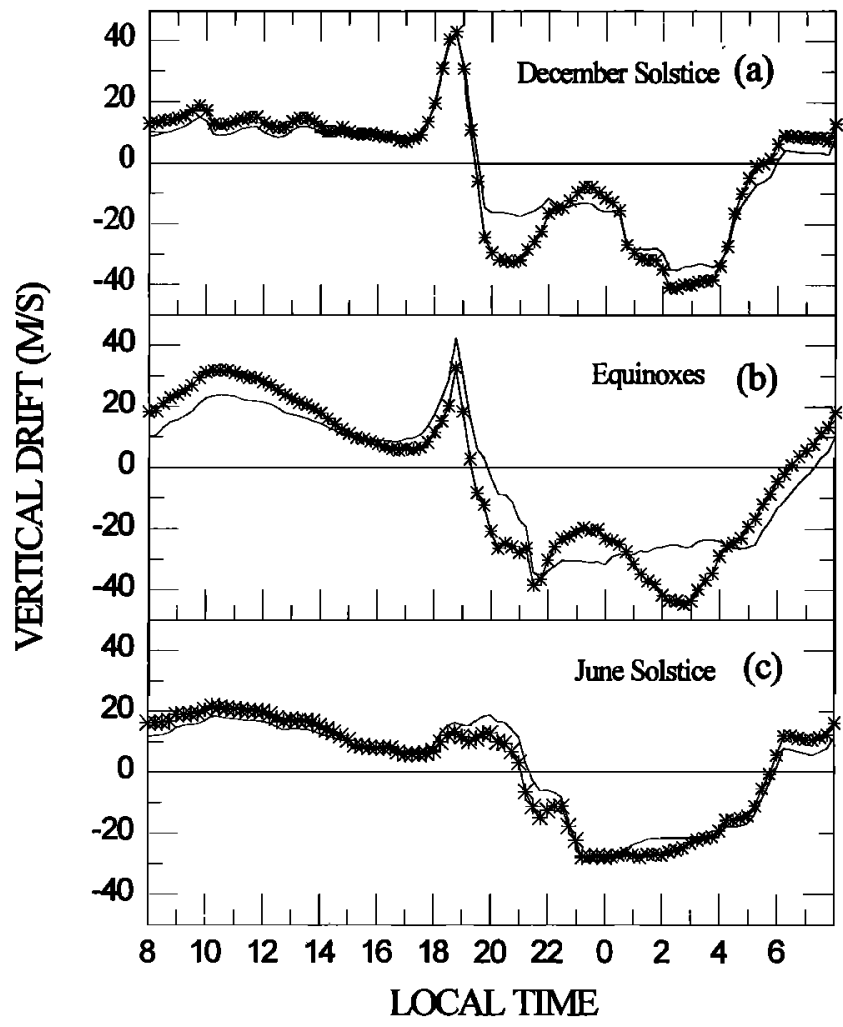

Figure 2. Vertical drift model (positive upward) for $F_{10.7}>150$ as a function of local time for Fortaleza (solid line, $350 \mathrm{~km}$ ) for (a) December solstice (D months), (b) equinoxes, and (c) June solstice ( $\mathrm{J}$ months). The curves with stars represent the vertical drift velocities at $300 \mathrm{~km}$ deduced for Cachoeira Paulista.

enhancement at sunset and again during presunrise hours, whereas for the remaining hours the gradient is mostly positive or height independent.

The vertical drift at $650 \mathrm{~km}$ thus obtained, when multiplied by $\cos (I)$ (where $I$ is the dip angle over Cachoeira Paulista) yields the vertical drift at the $h_{\max }$ height over Cachoeira Paulista. These results are presented as starred curves in Figures 2 and 3 for solar maximum and minimum, respectively. These are the $V_{z}$ values in (3) used to calculate the meridional wind based on the observed $h_{\max }$ variation.

\section{$F$ Layer Peak Height, $h_{\max }$, Over Cachoeira Paulista}

The $h_{\max }$ was calculated from the Cachoeira Paulista ionograms using the POLAN (Polynomial Analysis) true height analysis code [Titheridge, 1985] for the data set before 1990. A digisonde 256 became operational at Cachoeira Paulista in March 1990. The data collected since then was reduced for $h_{\max }$ values using the ARTIST code (Automatic Real Time Ionogram Scaler with True Height) [Reinisch et $a l ., 1989]$ available in the system. The data sets were grouped into summer ( $\mathrm{D}$ months), equinox, and winter ( $\mathrm{J}$ months) for high and low solar flux conditions. The mean daily variations of the $h_{\max }$ for the three seasons and for solar flux values $>150$ are presented in Figures $5 a, 5 b$, and $5 c$. It should be mentioned that the number of days of $h_{m} F_{2}$ data for high solar flux June solsticial months is only half of those used for other conditions. The day-to-day variations in the $h_{\max }$ are generally 


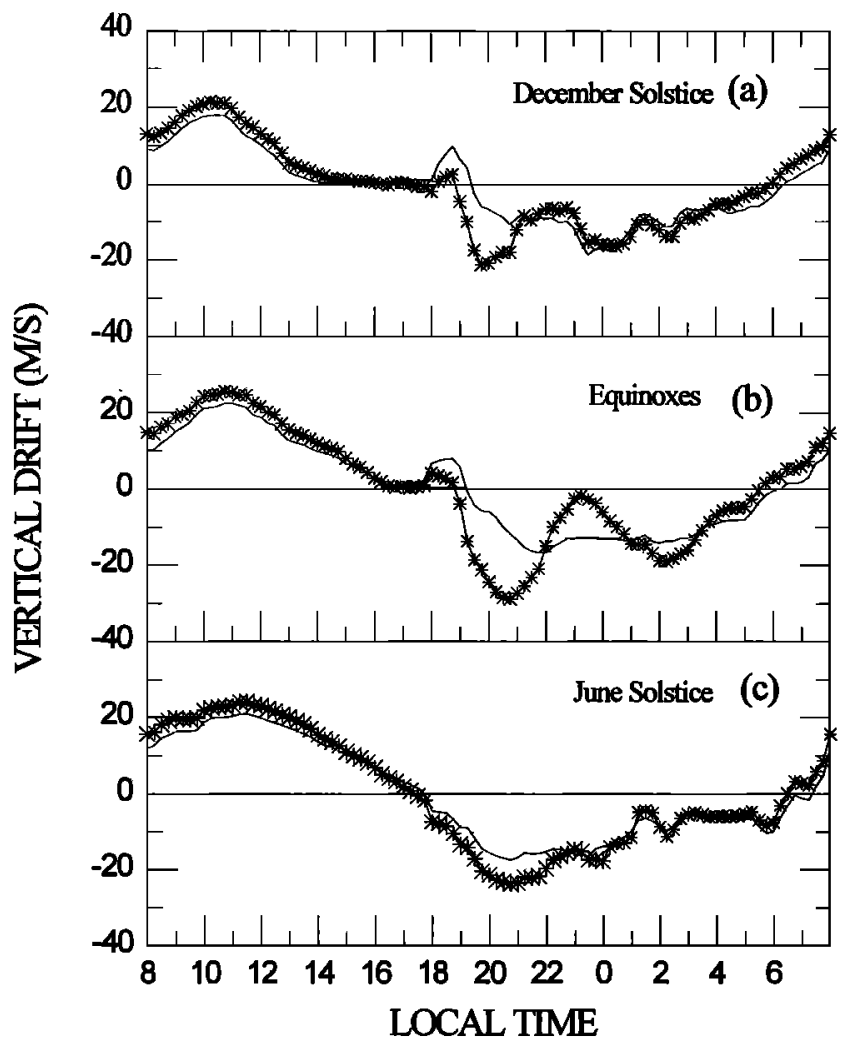

Figure 3. Vertical drift model for Fortaleza (solid line, 350 $\mathrm{km}$ ) as in Figure 2, but for $F_{10.7}<100$.

small since the standard deviation shown by the vertical bars did not exceed $\pm 26 \mathrm{~km}, \pm 25 \mathrm{~km}$ and $\pm 25 \mathrm{~km}$ for the three seasons, respectively. The $h_{\max }$ variations for the three seasons have some common features, the most notable being the large $h_{\max }$ values during the day maximizing around or after the midday. The increase of $h_{\max }$ from $\sim 1800 \mathrm{LT}$ to $\sim 2000 \mathrm{LT}$ is due to the prereversal enhancement ( $F$ region dynamo) electric field seen most dominant in summer months, less significant during equinox, and almost absent during winter months, as per the vertical drift models presented in Figures 2 and 3. It may be observed further that the ascending features in $h_{\max }$ seen from 0100 to $0600 \mathrm{LT}$ in $D$ months and equinoxes or from 0300 to $0600 \mathrm{LT}$ in $\mathrm{J}$ months occur when the equatorial electrodynamic drift of the plasma is known to be downward, whereas the descending features in $h_{\max }$ seen during several hours prior to $1800 \mathrm{LT}$ occur when the $E \times B$ drift is known to be upward. In view of the fact that the equatorial electric field maps along field lines to low latitudes, these trends in $h_{\max }$ would point to the existence of another mechanism, in this case meridional wind, that could cause displacement of plasma over low latitude in opposite sense to that produced by an $E \times B$ drift such as that shown in Figures 2 and 3.

The average diurnal patterns of $h_{\max }$ for $F_{10.7}<100$ are shown in Figures $6 \mathrm{a}, 6 \mathrm{~b}$, and $6 \mathrm{c}$ for summer, equinox, and winter months, respectively. The maximum values of the standard deviation in the day-to-day variability of the $F$ layer peak height are $\pm 29 \mathrm{~km}, \pm 29 \mathrm{~km}$, and $\pm 22 \mathrm{~km}$ for the three seasons, respectively. It may be noted that the $h_{\max }$ variations from $\sim 0600$ to $\sim 1700 \mathrm{LT}$ follow nearly similar patterns as those of solar maximum but presenting significantly smaller values (by $50-100 \mathrm{~km}$ ) for the three seasons. The largest difference in the $h_{\max }$ values (around $100 \mathrm{~km}$ ) occurs around $1800 \mathrm{LT}$ in the summer and equinoctial months and around $1500 \mathrm{LT}(\sim 80 \mathrm{~km})$ in winter months. The difference around $1800 \mathrm{LT}$ in the former case can be attributed to a corresponding solar activity dependence of the prereversal enhancement electric field (being larger for solar maximum and smaller for solar minimum), which dominates the summer and equinoctial epochs and not the winter months. Further points of comparison between solar maximum and minimum may be noted. The $h_{\max }$ values increase around $1800 \mathrm{LT}$ and decrease after $\sim 2000$ LT toward midnight during summer and equinoxes for $F_{107}>150$, whereas they increase from (lower values) around sunset to reach a stationary (higher values) around midnight for $F_{10.7}<100$. For the winter months the nighttime $h_{\max }$ values are nearly the same for both high and low solar flux levels. The decreasing trend of $h_{\max }$ after 2000 LT for higher solar flux (seen clearly for summer and equinoctial months) is produced by the large downward $E \times B$ drift $\left(20 \mathrm{~m} \mathrm{~s}^{-1}\right)$ that is present at these local times. As compared to this, the relatively smaller $\operatorname{drift}\left(\sim 5 \mathrm{~m} \mathrm{~s}^{-1}\right)$ for lower solar flux values makes other processes dominate the displacement of the $h_{\max }$ at these hours. During $\mathrm{J}$ months (winter) the heights at these hours follow similar stationary trends for both solar flux levels, which points to their insignificant control by the $F$ layer dynamo electric field.

\section{Determination of $\boldsymbol{h}_{\mathbf{0}}$ and $\boldsymbol{\alpha}$}

We denote by $h_{0}$ the height of the $F$ layer peak in the absence of ionization drift or transport under electric field or meridional wind, the equilibrium being established between the recombination and diffusion processes. Bounsanto et al.

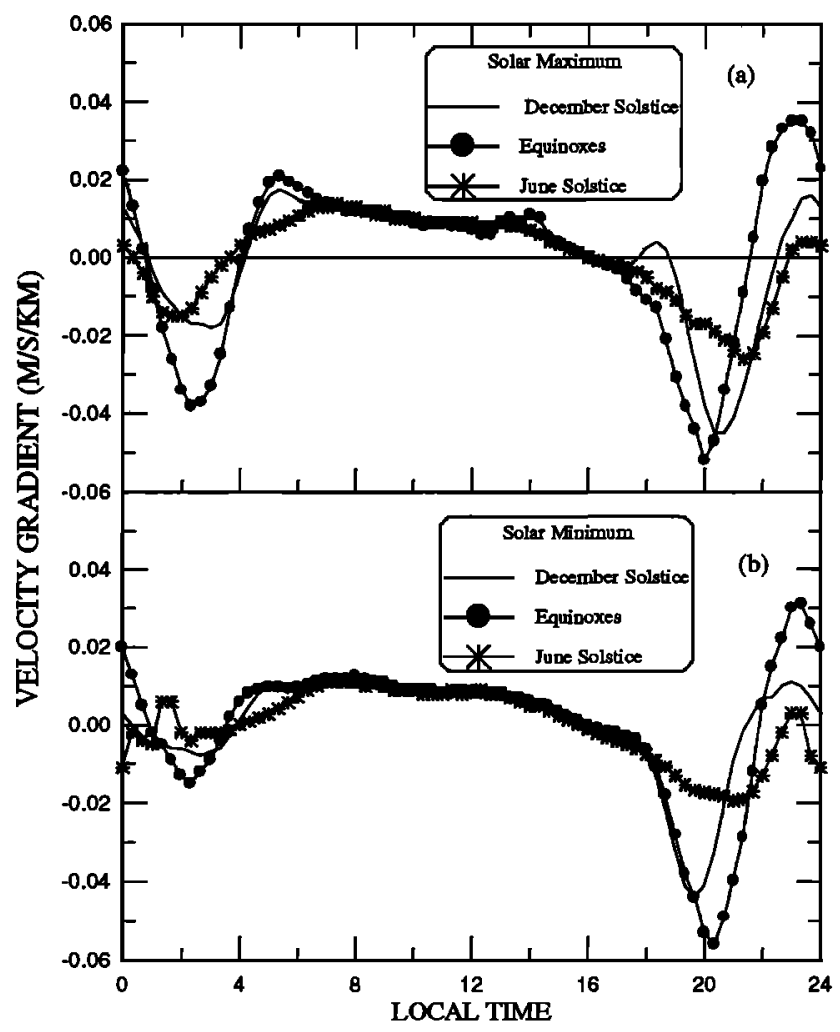

Figure 4. Vertical drift velocity gradients local time pattern at $350 \mathrm{~km}$ calculated using a model on $E$ and $F$ region electrodynamic coupling [Batista et al., 1986]. 


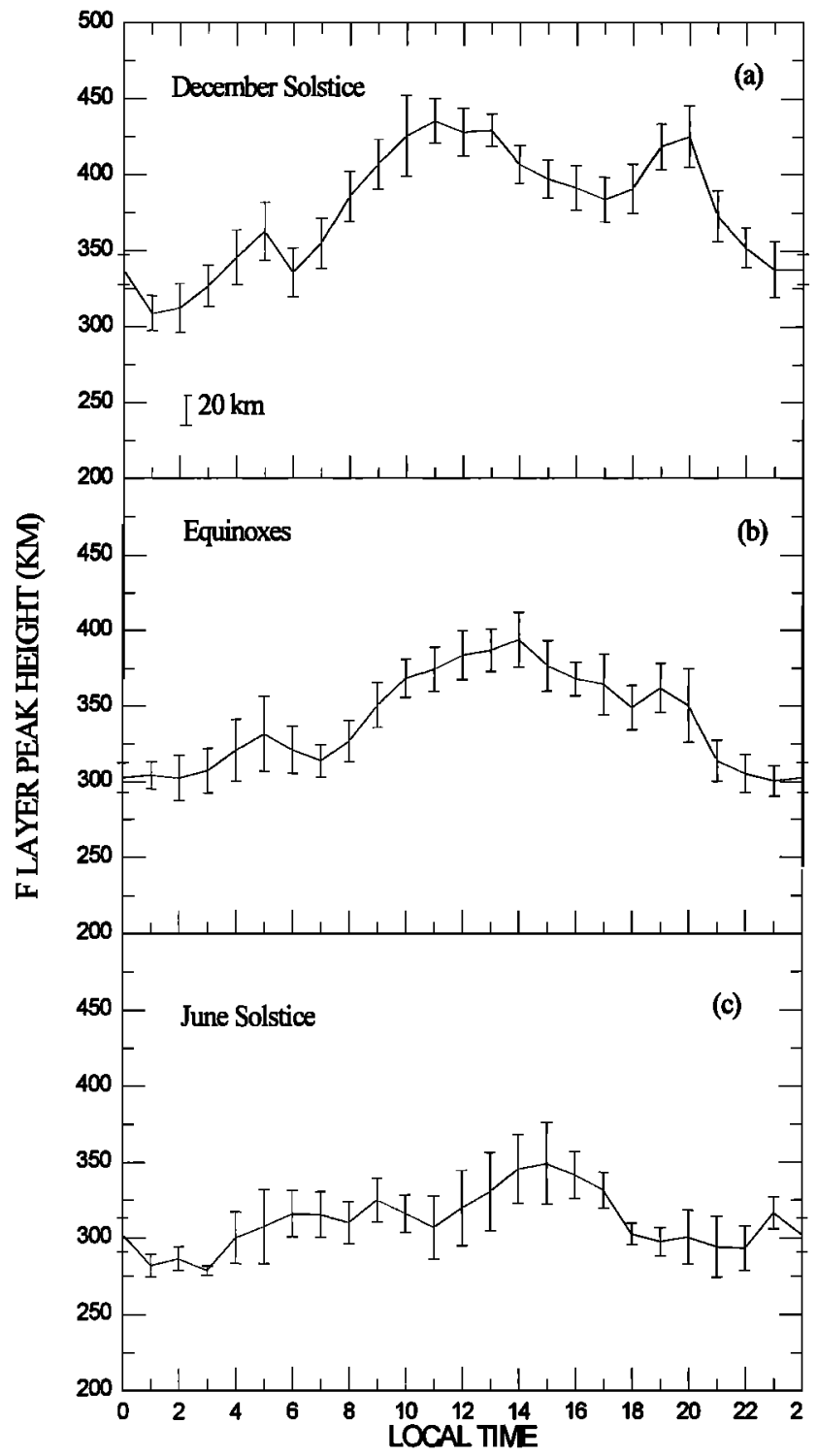

Figure 5. Diurnal pattern of the mean $h_{\max }$ values for $F_{107}>150$ representing (a) $\mathrm{D}$ months (November and December 1988, December 1990, January and December 1991), (b) equinoctial months (September and October 1988, September 1989, and March 1991), and (c) J months (May 1989 and June 1990). The vertical bars represent the standard deviation.

[1989] has shown that under certain $F$ region conditions the contribution from the rate of change of the $h_{\max }$ and from the nonlinearity of the terms in (3) are small. However, we have considered both of these contributions in our calculations. The relationship between $\beta$ and $D$ at the equilibrium height $h_{0}$ is given by $\beta=C D_{e, s} \sin ^{2} I / H^{2}$; the subscripts $e$ and $s$ represent day and night equilibrium conditions for which the values of $C$, as adopted from Bounsanto et al. [1989], are 1.077 and 0.160 , respectively; $H=0.058 \mathrm{~T}_{\alpha} \mathrm{km}$. The diffusion term (which may be denoted as $\delta$ ) was calculated using the expression for diffusion coefficient as given by Dalgarno [1964], and the recombination term was calculated using $\beta=10^{-8} \mathrm{n}\left(\mathrm{N}^{2}\right) \mathrm{s}^{-1}$ as a function of height. The MSIS-86 (Mass Spectrometer Incoherent Scatter) neutral atmospheric model was used for these calculations. The height at which $\beta-\delta=0$ is then taken as $h_{0}$ and the corresponding $D_{e, s}$ values being used to calculate $\alpha$ given by (4). Day-night transition for the value of $C$ was assumed to be linear so that its values were $C$ $=0.771$ at $0500 \mathrm{LT}$ and $1700 \mathrm{LT}$; and $C=0.466$ at $0400 \mathrm{LT}$ and $1800 \mathrm{LT}$. The local time pattern of the $h_{0}$ values thus obtained are presented (solid line) for the three seasons and solar flux values $>150$ and $<100$, respectively, in Figures $7 \mathrm{a}$ and $7 \mathrm{~b}$. Also presented in these figures for comparison are the corresponding $h_{\max }$ values of Figures 5 and 6 . The values of $h_{0}$ and $h_{\max }$ in Figures $7 \mathrm{a}$ and $7 \mathrm{~b}$ appear to suggest that the linearization of (3) proposed by Miller et al. [1989] and Bounsanto et al. [1989] is not always valid in the present analysis since the difference between the two parameters is not always small enough to make the higher-order terms negligible. The diurnal variation of $h_{0}$ shows a maximum around $1900 \mathrm{LT}$ and a minimum around $0600 \mathrm{LT}$. These features are consequences of the day-night transition factors adopted in the model. The diffusion term $(\delta)$ starts

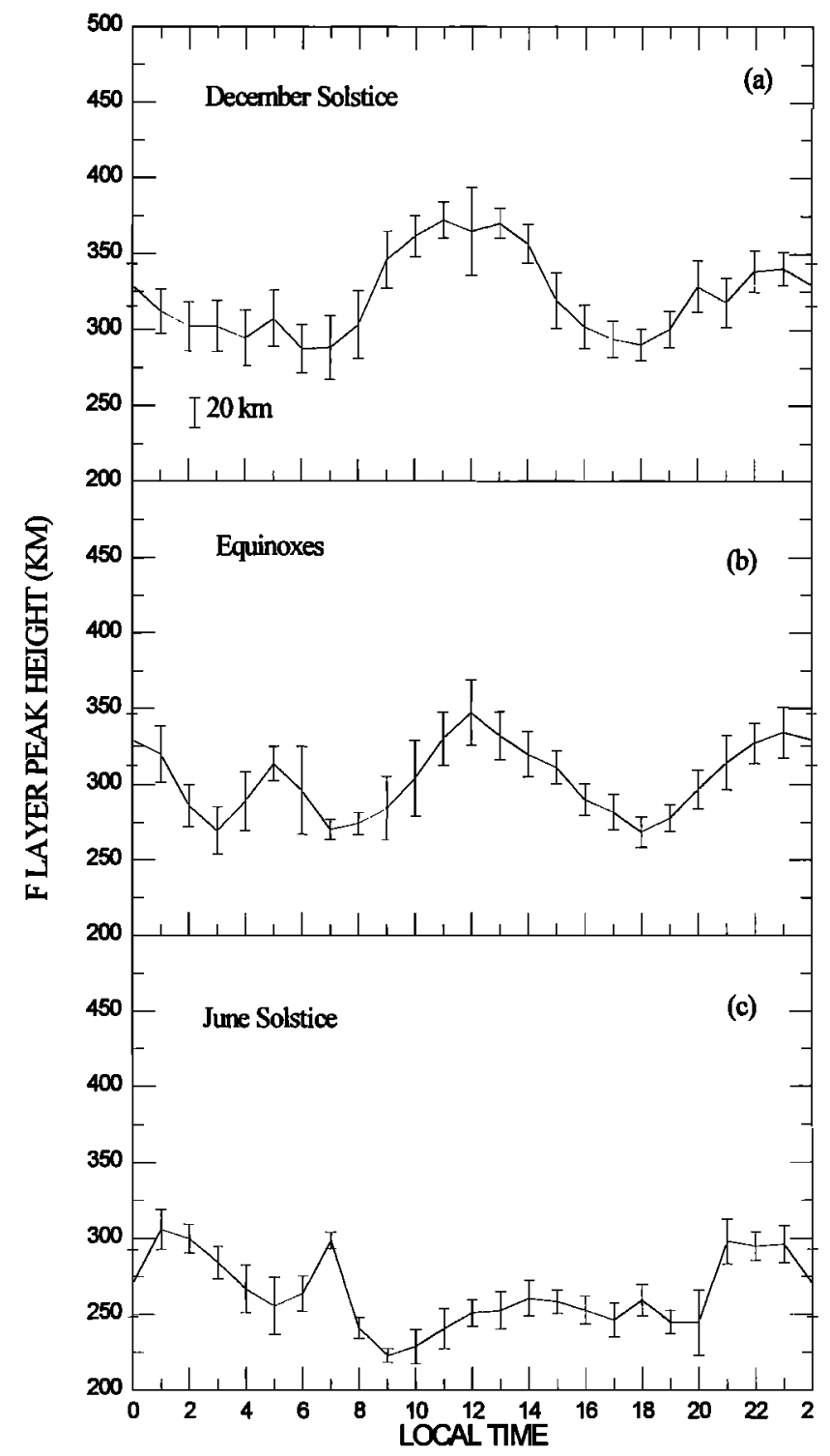

Figure 6. Diurnal pattern of the mean $h_{\max }$ values for $F_{107}<100$ representing (a) $\mathrm{D}$ months (November and December 1985, and January and February 1986), (b) equinoxes (March, April, and October 1985), and (c) J months (May, June, July, and August 1986). 


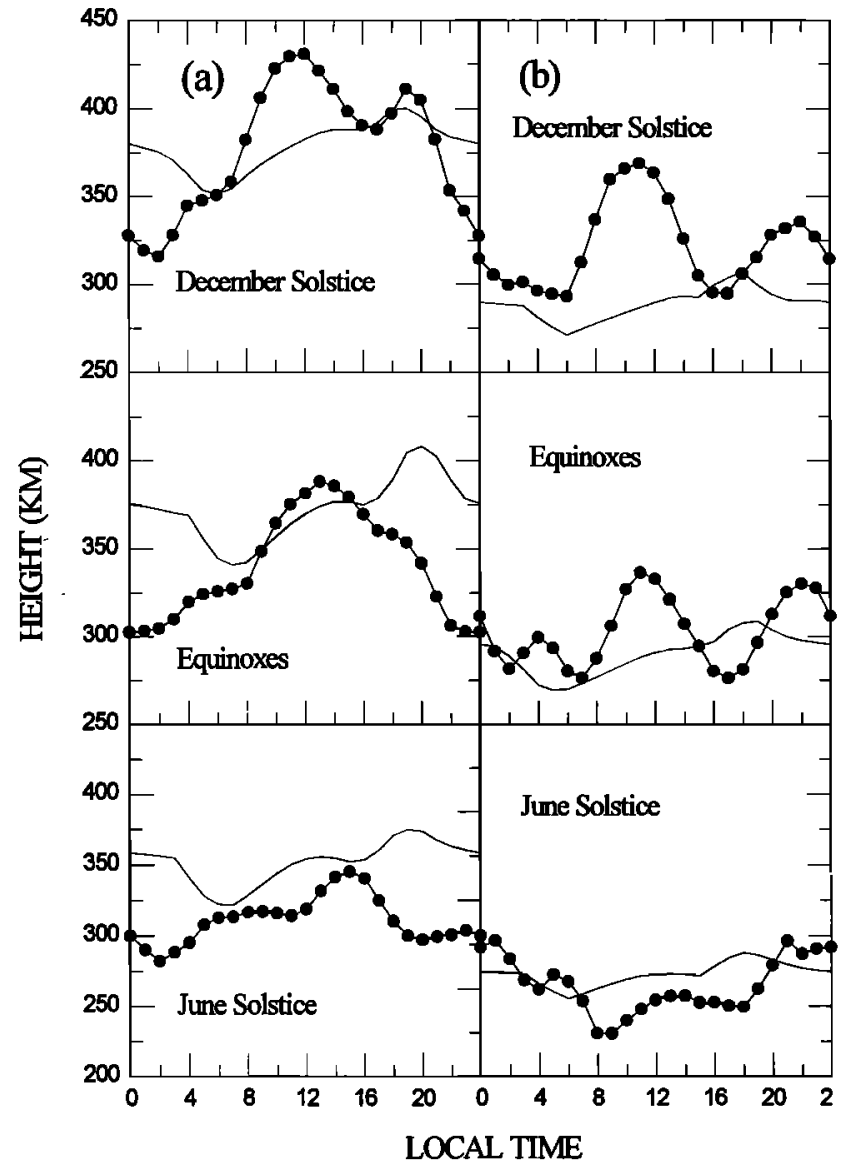

Figure 7. The diurnal variation of $h_{0}$ (solid line) representative of three seasons (a) for $F_{107}>150$ and (b) for $F_{10.7}<100$. The curves with solid dots are the corresponding $h_{\max }$ values.

decreasing (increasing) after 1600 LT (0400 LT) and, consequently, the $\beta-\delta=0$ condition will hold at higher (lower) altitudes. It may be noted further in Figures $7 \mathrm{a}$ and $7 \mathrm{~b}$ that even though the values of $h_{0}$ and $h_{\max }$ have decreased from solar maximum to minimum epoch, certain characteristics of their relative importance appear to remain the same. For example, for daytime conditions of summer and equinoctial months $h_{0}<h_{\max }$, and for winter months the situation is inverted. At solar maximum the dominant situation is $h_{0}>h_{\max }$ throughout the night, starting from $\sim 1600$ LT during equinox and winter and from $\sim 2100$ LT in December solstice. However, for solar minimum the condition $h_{0}<h_{\max }$ dominates in December solstice and less so in equinoxes. During June solstice the gross feature is that $h_{0}>h_{\max }$ during the day and $h_{0}<h_{\max }$ during the night. The situation during solar minimum is especially noteworthy since even though the nighttime $E \times B$ drift is downward at night, the $h_{\max }$ continues to increase during the pre-midnight hours, a trend somewhat opposite to that observed during solar maximum. The relative importance of the meridional wind is manifest in these contrasting $h_{0}$ versus $h_{\max }$ relationship between solar maximum and minimum.

\section{Results of Magnetic Meridional Winds}

Using the information on $V_{z}, h_{\max }, h_{0}$, and $\alpha$, (3) can now be used to calculate the meridional wind $U_{M}$. The results for the three seasons of high solar flux $\left(F_{10.7}>150\right)$ and magnetically quiet conditions are presented in Figure 8 (solid line). In order to smooth out rapid steps of the values we have used an 8degree polynomial fit of these curves, the results being represented by solid line curves. Also shown in this figure are the meridional winds at $350 \mathrm{~km}$ according to the HWM-90 of Hedin et al. [1991]. It may be observed that in D months the experimental results show equatorward winds of a few hours' duration before and after midnight, and poleward wind between 0500 and 1900 LT and between 2200 and 0200 LT. In $\mathrm{J}$ months the wind is predominantly poleward for most local times. For equinoctial months the wind is equatorward between 0200 and $0600 \mathrm{LT}$ and predominantly poleward at all other local times. A comparison with the wind in magnetic meridional direction from HWM-90 shows some broad agreement, with respect to magnitude and direction, between the experimental results of this analysis. However, there exists a certain degree of phase difference between the model and observation with respect to the maxima, minima, and the hours of inversion of the winds. For example, in D months there is a postmidnight maximum centered around $0300 \mathrm{LT}$ in our result, whereas the HWM-90 shows a broad maximum around $0700 \mathrm{LT}$; also the inversion to poleward in the observational data occurs around $0600 \mathrm{LT}$, whereas the HWM-90 has it at 1400 LT. A better agreement between the observational results and the model exists for equinoctial and J months.

The results of meridional wind over Cachoeira Paulista derived from (3) and, its polynomial fit, together with the representation by the HWM-90, for $F_{107}<100$ are presented in Figure 9. In the case of D months it may be noted that the wind is predominantly equatorward for most of the local times, and between 1300 and $1800 \mathrm{LT}$ it is poleward. In the J months the calculated wind shows large amplitude in poleward direction from $0600 \mathrm{LT}$ to $1800 \mathrm{LT}$ and equatorward between $1800 \mathrm{LT}$ and $0600 \mathrm{LT}$. The equinoctial months show winds similar to those of $\mathrm{J}$ months but with smaller amplitude. Comparison with the HWM-90 shows somewhat better agreement for D months in amplitude and direction even though there exists certain phase differences between the maxima and minima of the two curves. It may be noted that after $2000 \mathrm{LT}$ the winds derived from our data are equatorward in all three seasons, whereas the HWM-90 does not show such a feature in June and equinoctial months. This aspect of our results may be appreciated better by comparing the $h_{\max }$ values after $2000 \mathrm{LT}$ which for solar maximum has a decreasing trend in $\mathrm{D}$ months and equinoxes, or a stationary trend as seen during $\mathbf{J}$ months, whereas during solar minimum the $h_{\max }$ shows increasing trend. On the other hand, the $E \times B$ drift which is downward at these hours (Figures 2 and 3 ) cannot produce the increase in the heights observed during the solar minimum. Therefore this rise in the height during solar minimum is a rather clear manifestation of the existence of an equatorward wind (required to lift up the layer) which is as shown in Figure 9.

\section{Comparison With Results From $\boldsymbol{F}$-P Measurements}

Fabri-Perot interferometer measurements of the Doppler displacement of the $630 \mathrm{~nm}$ atomic oxygen emission line has been utilized to determine meridional and zonal winds over Cachoeira Paulista. Such measurements are not available 


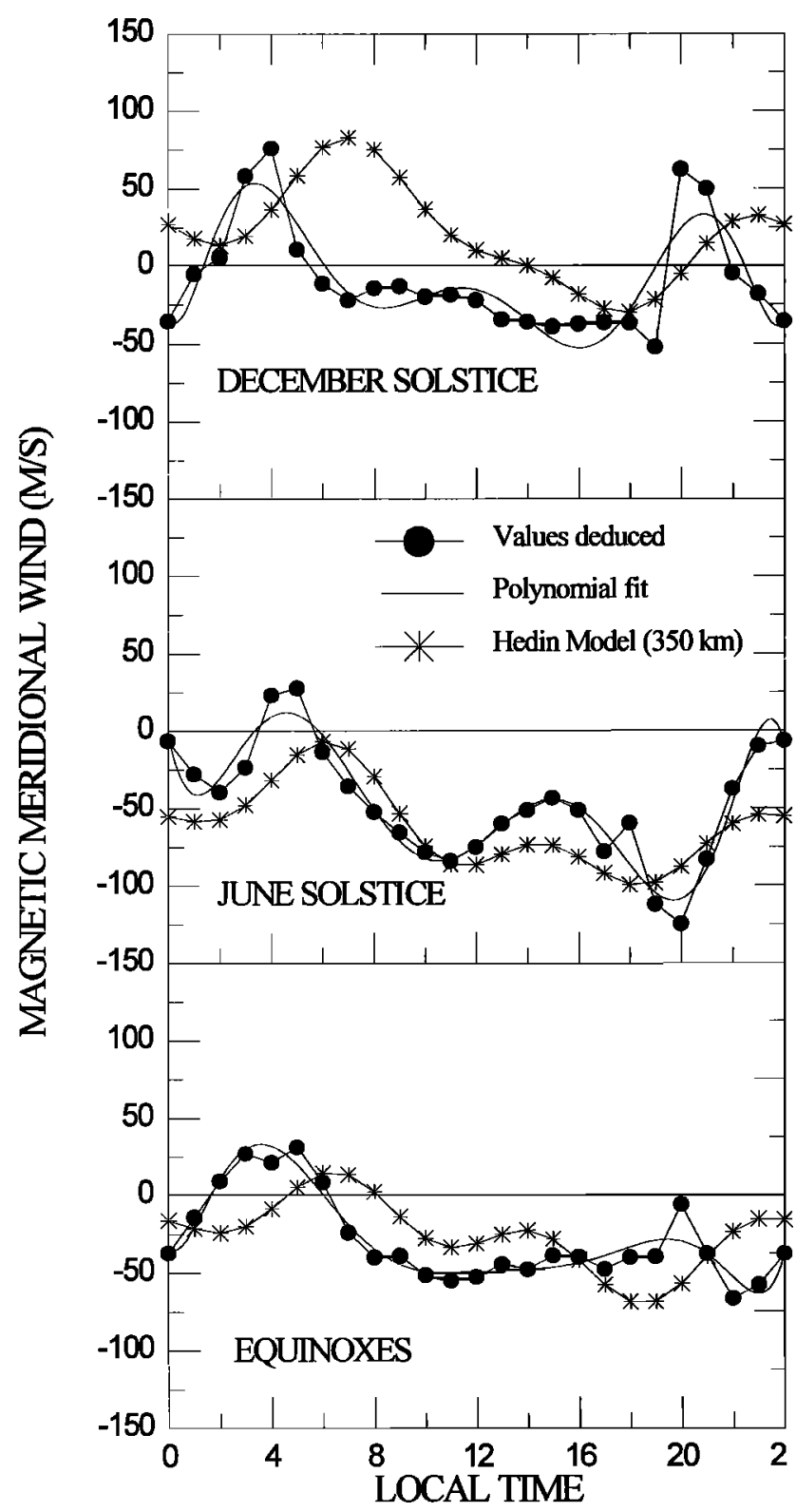

Figure 8. The diurnal variation of the meridional wind $U_{M}$ (solid dots) based on the observed $h_{\max }$ values and (3) for $F_{107}>150$ and representative of three seasons. Solid line curves are 8-degree polynomial fit to the solid curve. The curves with stars are the meridional winds at $350 \mathrm{~km}$ according to HWM-90 (positive is northward).

simultaneous with the ionograms analyzed here. However, the results published by Sahai et al. [1992] correspond to an epoch, that is, between March 1988 and December 1989, belonging to the solar maximum epoch data sample utilized in the present study (see Figure 1). Therefore a comparison of the two sets of results seems to be meaningful. The zonal $\left(V_{G}\right)$ and meridional $\left(U_{G}\right)$ winds measured by $F-P$ technique are projected (using the magnetic declination angle $D$ ) to obtain the wind in the magnetic meridional direction given by $U_{M}=V_{G} \cos D+U_{G} \sin D$. The magnetic meridional wind thus obtained are plotted together with our results for $D$ months, equinoxes, and $\mathrm{J}$ months in Figures $10 \mathrm{a}, 10 \mathrm{~b}$, and $10 \mathrm{c}$, respectively. The vertical bars on the $F-P$ data represent the standard deviation. The results seem to agree better in $\mathbf{J}$ months, with reasonably good agreement also present in the premidnight hours of $\mathrm{D}$ months and equinoxes. During $\mathrm{D}$ solstice postmidnight hours' significant difference between the two results is observed in the magnitudes of the velocities. However, consideration of the large standard deviation of the $F-P$ measurements might diminish somewhat the degree of the disparity. Similar reasoning can be considered valid for the equinox as well. Overall, the results presented here point to reasonable agreement of the results from the two techniques to measure the magnetic meridional wind.

\section{Discussion}

The meridional wind calculated for midlatitude from the $h_{\max }$ database has been validated by comparison with results of meridional wind measured by the Millstone Hill incoherent scatter radar in the paper by Miller et al. [1986]. Such validation is not possible in the case of our results for low latitudes where no incoherent radar data are available (except for Arecibo, Puerto Rico, which, however, is at the edge of the latitude limit as far as the electric field effect on $h_{\max }$ is concerned). On the other hand, it is desirable to verify the conditions of validity and accuracy of the present results in view of the advantage the method offers for calculating the wind for all local times as compared to the nighttime only measurements, often during restricted local times, possible by the $F-P$ technique. We have addressed this point by identifying the input parameters, that is, $h_{\max }, V_{z}$, and $h_{0}$ to which the calculated meridional winds are most sensitive. Thus we carried out an evaluation of the relative importance of each of the terms of (3) for the calculation of the meridional wind. The contributions of each of the following terms are considered separately.

For the day

$$
\begin{gathered}
D_{1}=\frac{1}{\cos I \sin I} \frac{d h_{\mathrm{m}}}{d t} ; \\
D_{2}=\frac{H}{(k+1) \alpha}\left[e^{\frac{h_{1 n}-h_{0}}{H}}-\lambda e^{-k \frac{h_{m}-h_{0}}{H}}\right] ; \\
D_{3}=-V_{z} / \sin I .
\end{gathered}
$$

For the night

$N_{1}=D_{1} ; N_{2}=D_{2}($ when $\lambda=1) ; N_{3}=D_{3}$.

The results are presented in Figure 11a for the three seasons of high solar flux. The terms that dominate in the determination of the wind are $D_{2}, N_{2}$ and $D_{3}, N_{3}$ It may be noticed that the term in vertical drift/electric field has significant contribution at all local times. Therefore it is clear that in the use of $F$ layer peak displacement for obtaining meridional winds over low latitudes, the electric field contribution cannot be ignored, as is probably the case for midlatitude [Miller et al., 1989]. A clear example of the influence of the electric field can be demonstrated by considering Figure $7 \mathrm{a}$ in which the June solsticial values of $h_{\max }$ are almost constant from $2200 \mathrm{LT}$ to $2400 \mathrm{LT}$. However, 


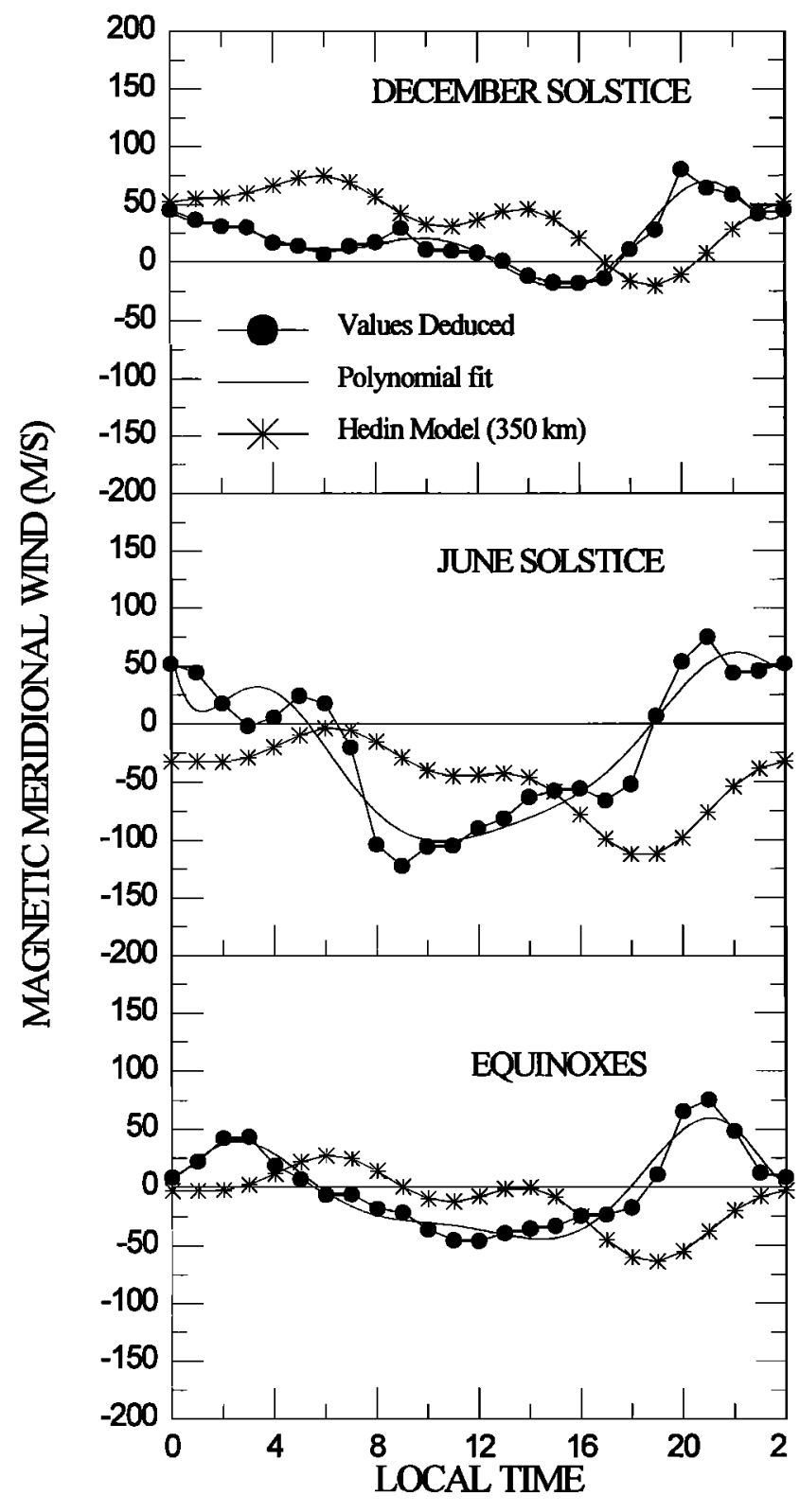

Figure 9. Results similar to those of Figure 8, but for low solar flux $\left(F_{10}<100\right)$.

if the term in $D_{3}, N_{3}$ (from the vertical drift) shown in Figure 11 is not considered, the term in $D_{2}, N_{2}$ would have been dominant and negative (southward) which should have caused downward displacement of the $h_{\max }$ at these hours. Thus the observed steady values can be reproduced only if we include the vertical drift term which is in fact very significant at these hours. The contributions from $D_{2}, N_{2}$ and $D_{3}, N_{3}$ terms have comparable significance for low solar flux values as well, as seen in Figure $11 \mathrm{~b}$. In this case the meridional wind during night is always equatorward, as was in Figure 9, due to the fact that the corresponding terms in $N_{2}$ and $N_{3}$ are always positive, whereas in the case of Figure $11 \mathrm{a}$ the term of $N_{2}$ is negative while that of $N_{3}$ is positive.

Another possible source of uncertainty arises from the diffusion velocity and an apparent velocity arising from recombination effects. These are given by $v_{D}=D H \sin I$ and $v_{\beta}=\beta H$, respectively. Their contributions at $h_{0}$ were evaluated and found to be only a very small fraction of the meridional wind for most of the time. They can be accounted for if necessary for specific cases. In any case they have almost negligible effect for determining the shape of the diurnal pattern, or of shorter-term variations such as could arise under disturbed conditions, of the meridional wind. Perhaps the most significant point of validity of the winds obtained from the present analysis hangs on the fact that their magnitudes are comparable to the measurements by $F-P$ technique and with the HWM-90 as the results of comparisons in Figures 8, 9, and 10 show. The differences in the phases of the maxima/minima between our results and those of $F-P$ measurements might be mainly due to the fact of nonsimultaneity of the two types of observational data sets, whereas differences with the HWM-90 might point to inadequate data input to this model from the geographic region of our measurements.

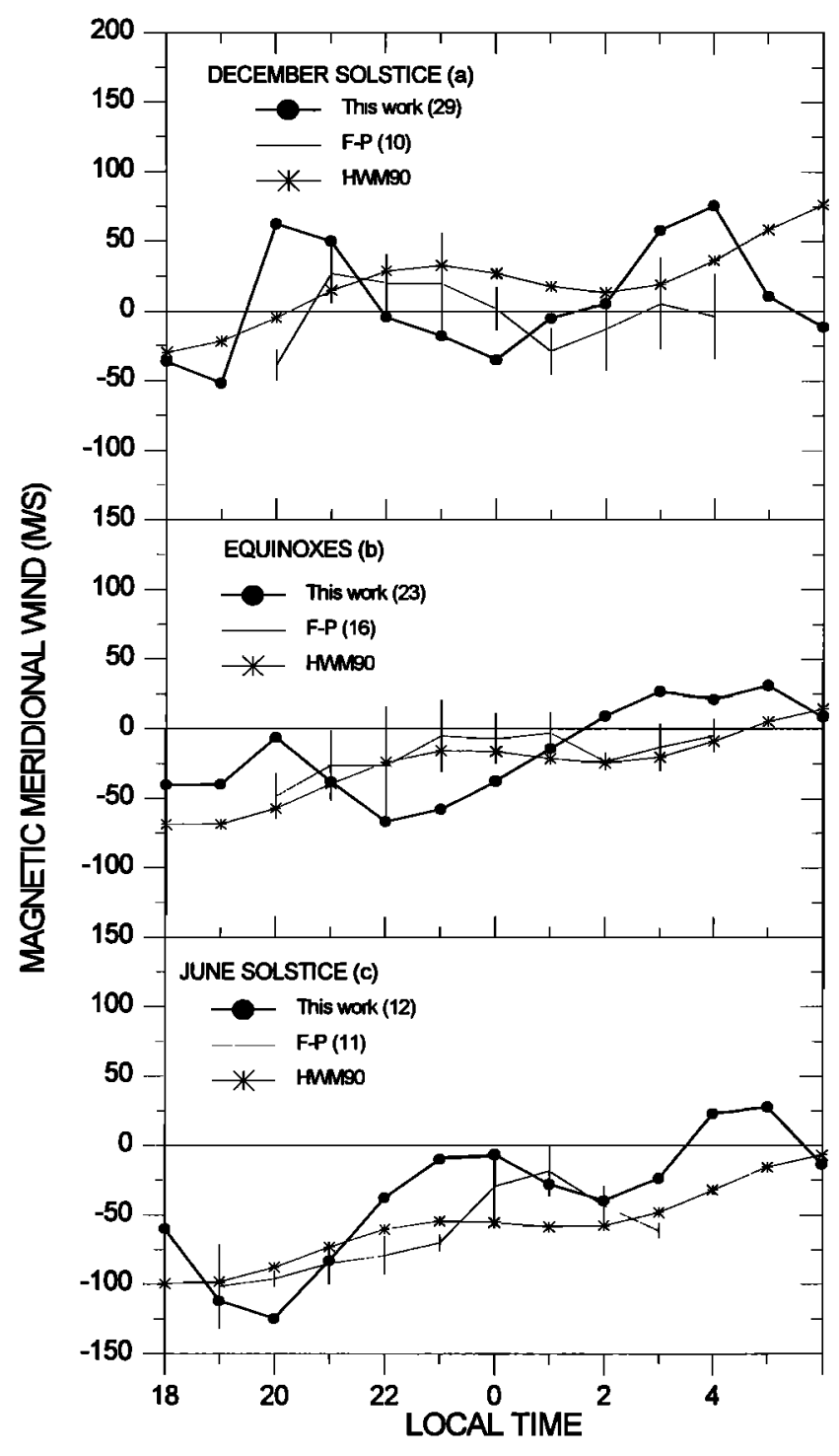

Figure 10. Comparison of $U_{M}$ obtained from the present analysis (lines with dots) and the magnetic meridional wind from $F-P$ measurements over Cachoeira Paulista for (a) D months, (b) equinoxes, and (c) $J$ months. The number in parentheses shows the number of data points. 


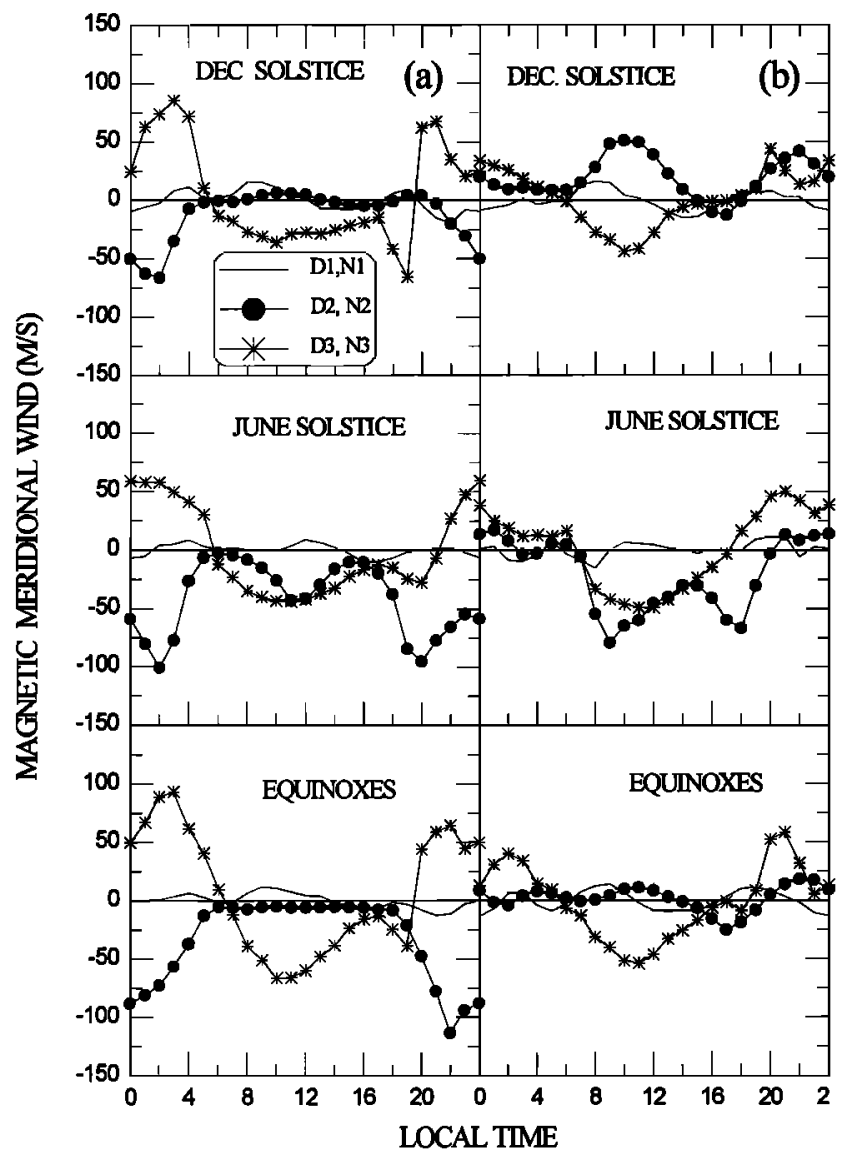

Figure 11. Diurnal variation of the contributions to the meridional wind arising from the three terms constituting (4): (a) for $F_{107}>150$ and (b) for $F_{10.7}<100$.

\section{Concluding Remarks}

We have developed a method for determining the magnetic meridional component of the thermospheric winds for low latitudes based on the servo model for the $F$ layer [Rishbeth, 1967; Rishbeth et al., 1978] which expresses the displacement of the layer peak height as a function of chemical loss, diffusion, vertical plasma drift/zonal electric field and meridional component of the neutral wind. The servo model has been widely used for midlatitude conditions [Miller et al., 1986; Bounsanto et al., 1989] where the role of electric field can be considered negligible. However, for low latitudes the electric field control of the peak height is significant. Our major task in this analysis was therefore to develop an electric field model for Cachoeira Paulista for which the $h_{\max }$ data from ionosonde are analyzed. This was accomplished by first determining the vertical drift diurnal pattern for the equatorial station, Fortaleza, which was based on Jicamarca vertical drift data [Fejer et al., 1979, 1995], except for local time interval between $1700 \mathrm{LT}$ and $2200 \mathrm{LT}$ when the vertical drift was based on the ionosonde data from Fortaleza. This procedure was necessary because of the well-known difference in the $F$ region dynamo electric field development around sunset between the Peruvian and Brazilian longitude sectors [ $[A b d u$ et al., 1981]. The electric field, valid for $350 \mathrm{~km}$, was then extrapolated, using an electrodynamic model [Batista et al., 1986], to the apex height of the magnetic field line that maps to the altitude of the $h_{\max }$ over Cachoeira Paulista, thus providing the necessary vertical drift pattern to be used, together with the $h_{\max }$ data from ionograms, to calculate the meridional winds over Cachoeira Paulista. The meridional winds were calculated for all three seasons, and solar maximum and minimum and magnetically quiet conditions. The main conclusions from the present investigations are the following: The equatorial low-latitude electric field/vertical drift present significant seasonal and solar activity dependences. This is most evident in the prereversal enhancement electric field near sunset whose amplitude is largest in D months and smallest in J months, with intermediate values during equinoctial months. It shows high (low) values for $F_{107}>150(<100)$ and is absent totally for $\mathrm{J}$ months of low solar flux values. The vertical drift presents height gradients according to the $E$ and $F$ region electrodynamic coupling model, the gradient being negative with altitude during sunset, postsunset, and presunrise hours, with positive gradients for the remaining hours in agreement with results from Jicamarca radar. The $h_{\max }$ over Cachoeira Paulista is always higher during solar maximum than during solar minimum, independent of the season except during 2200-0200 LT when their values during solar minimum are equal to or higher than during solar maximum. The vertical drift prereversal enhancement electric field manifestation in $h_{\max }$ diurnal pattern is evident in D months and equinoxes of high solar flux (Figures $2 a$ and $2 b$ ) and is difficult to identify for low solar flux (Figures $3 a, 3 b$, and $3 c$ ). The term in the vertical drift/electric field in the servo model makes significant contribution to the peak height displacement so that the method of determining the meridional wind from such $h_{\max }$ displacements should always include a realistic electric field model for low-latitude conditions. The meridional winds calculated for solar maximum conditions over Cachoeira Paulista show general agreement (especially in magnitudes) with the HWM-90 results. However, for solar minimum conditions the differences are more marked. The reliability of our results as compared to the HWM-90 seems to be reasonably good as can be judged from an example of equatorward wind after $1900 \mathrm{LT}$ in J months of solar minimum, which is as expected (from the ascending trend of $h_{\max }$ at these hours) in contrast to the poleward wind predicted by the model.

The meridional wind calculated for high solar flux values over Cachoeira Paulista show reasonably good agreement with measurements by $F-P$ technique for similar solar activity conditions, which strengthens further the confidence in our results and therefore of the electric field model determined for Cachoeira Paulista. Further analysis and investigation are continuing for a better understanding of the meridional wind patterns over Cachoeira Paulista under geomagnetically quiet and disturbed conditions.

Acknowledgements. The authors acknowledge support in the form of fellowships received from Conselho Nacional de Desenvolvimento Científico e Tecnológico - CNPq and CAPES. The digisonde at Cachoeira Paulista was acquired with partial support from the Fundação de Amparo à Pesquisa do Estado de São Paulo FAPESP.

The Editor thanks N. Balan and G. J. Bailey for their assistance in evaluating this paper.

\section{References}

Abdu, M.A., J.A. Bittencourt, and I.S. Batista, Magnetic declination control of the equatorial F-region dynamo electric field 
development and spread $F, J$. Geophys. Res., 86, 11443-11446, 1981.

Abdu, M.A., I.S. Batista, J.H.A. Sobral, B.G. Fejer, and E.P. Szuszczewicz, Equatorial $F$-region dynamo electric field height/latitude structure: Solar cycle dependence from SUNDIAL data set, paper presented at STEP Symposium/5th COSPAR Colloquium, Sci. Comm. for Sol. Terr. Phys., Baltimore, Md., Aug. 24-28, 1992.

Balan, N., B. Jayachandran, R. Balachandran Nair, S.P. Namboothiri, G.J. Bailey, and P.B. Rao, HF Doppler observations of vector plasma drifts in the evening $F$-region at the magnetic equator, J. Atmos. Terr. Phys., 54, 1545-1554, 1992.

Batista, I.S., M.A. Abdu, and J.A. Bittencourt, Equatorial $F$ region vertical plasma drifts: Seasonal and longitudinal asymmetries in the American sector, J. Geophys. Res., 9], 12055-12064, 1986.

Batista, I.S., R.T. Medeiros, M.A. Abdu, J.R. de Souza, G.J. Bailey, and E.R. de Paula, Equatorial ionospheric vertical plasma drift model over the Brazilian region, J. Geophys. Res., 101, 10887$10892,1996$.

Bittencourt, J.A., and M.A. Abdu, Theoretical comparison between apparent and real vertical ionization drift velocities in the equatorial $F$ region, J. Geophys. Res., 86, 2451-2454, 1981.

Bounsanto, M.J., J.E. Salah, K.L. Miller, W.L. Oliver, R.G. Burnside, and P.G. Richards, Observations of neutral circulation at mid-latitudes during the equinox transition study, J. Geophys. Res., 94, 16987-16997, 1989.

Dalgarno, A., Ambipolar diffusion in the $F$ region, J. Atmos. Terr. Phys., 26, 939, 1964

Fejer, B.G., D.T. Farley, R.F. Woodman, and C. Calderon, Dependence of equatorial $F$ region vertical drifts on season and solar cycle, J. Geophys. Res., 84, 5792-5796, 1979.

Fejer, B.G., E.R. de Paula, S.A. Gonzalez, and R.F. Woodman, Average vertical and zonal drifts over Jicamarca, J. Geophys Res., 96, 13901-13906, 1991.

Fejer, B.G., E.R. de Paula, R.A. Heelis, and W.B. Hanson, Global equatorial ionospheric vertical plasma drifts measured by the AE-E satellite, J. Geophys. Res., 100, 5769-5776, 1995.

Hedin, A.E., et al., Revised global model of thermospheric winds using satellite and ground-based observations, J. Geophys. Res., 96, 7657-7688, 1991.

Heelis, R.A., P.C. Kendall, R.J. Moffet, D.W. Windle, and H. Rishbeth, Electrical coupling of the $E$ and $F$ regions and its effect on $F$ region drifts and winds, Planet. Space Sci., 25, 743-756, 1974

Miller, K.L., D.G. Torr, and P.G. Richards, Meridional winds in the thermosphere derived from measurement of layer height, $J$. Geophys. Res., 91, 4531-4535, 1986.
Miller, K.L., J.E. Salah, and D.G. Torr, The effect of electric fields on measurements of meridional neutral winds in the thermosphere, Ann. Geophys., 5A(6), 337-342, 1987.

Miller, K.L., P.G. Richards, and D.G. Torr, The derivation of meridional neutral winds in the thermosphere from F2-layer height, in World Ionosphere Thermosphere Study, edited by C.H. Liu, pp. 439-471, Sci. Comm. for Sol. Terr. Phys., Urbana, Ill., 1989.

Pingree, I.E., and B.G. Fejer, On the height variation of the equatorial $F$ region vertical plasma drifts, J. Geophys. Res., 92, 4763-4766, 1987.

Reinisch, B.W., K. Bibl, D.F. Kitrosser, G.S. Sales, J.S. Tang, Z.-M Zhang, T.W. Bullet, and J.A. Ralls, The digisonde 256 ionospheric sounder, in World Ionosphere Thermosphere Study, edited by C.H. Liu, pp. 350-382, Sci. Comm. for Sol. Terr. Phys., Urbana, Ill., 1989.

Richards, P.G., and D.G. Torr, Seasonal, diurnal, and solar cycle variations of the limiting $H$-flux in the Earth's topside ionosphere, J. Geophys. Res., 90, 5261-5268, 1985.

Richards, P.G., and D.G. Torr, Ratio of photoelectron to EUV ionization rates for aeronomic studies, J. Geophys. Res., 93, 4060-4066, 1988.

Rishbeth, H., The effect of winds on the ionosphere F2-layer, $J$. Atmos. Terr. Phys., 29, 225-238, 1967.

Rishbeth, H., S. Ganguly, and J.C.G. Walker, Field-aligned and field-perpendicular velocities in the ionospheric F2-layer, $J$. Atmos. Terr. Phys., 40, 767-784, 1978.

Sahai, Y., H. Takahashi, P.R. Fagundes, B.R. Clemesha, N.R Teixeira, and J.A. Bittencourt, Observations of thermospheric neutral winds at $23^{\circ} \mathrm{S}$, Planet. Space Sci., 40, 767-773, 1992.

Titheridge, J.E., Ionogram analysis with generalized POLAN, Rep. UAG-93, World Data Cent. A for Sol. Terr. Phys., NOAA, Boulder, Colo., 1985.

Young, E.R., D.G. Torr, P. Richards, and A.F. Nagy, A computer simulation of the midlatitude plasmasphere and ionosphere, Planet. Space Sci., 28, 881-893, 1980.

M. A. Abdu and I. S. Batista, Instituto Nacional de Pesquisas Espaciais, INPE, Av. dos Astronautas, 1758-C.P. 515, 12201-970, São José dos Campos, SP, Brazil. (email: abdu@dae.inpe.br; inez@dae.inpe.br).

R. T. de Medeiros, Universidade Federal do Rio Grande do Norte, UFRN, Campus Universitário-Lagoa Nova, 59072-970, Natal, RN, Brazil. (email: rui@dfte-lab.ufm.br).

(Received October 1, 1996; revised March 12, 1997; accepted March 13, 1997.) 